Journal of Computer Science 8 (10): 1730-1738, 2012

ISSN 1549-3636

(C) 2012 Science Publications

\title{
Simulation and Implementation of Quasi Resonant DC-DC Converter
}

\author{
${ }^{1}$ Parvathy, P. and ${ }^{2}$ N. Devarajan \\ ${ }^{1}$ Anna University Coimbatore, Tamilnadu, India \\ ${ }^{2}$ Department of Government, \\ College of Technology Electrical Engineering Coimbatore, Tamilnadu, India
}

\begin{abstract}
Problem statement: A half-bridge LLC resonant converter with a voltage doubler rectifier has a simple structure and its Zero-Voltage-Switching (ZVS) capability is excellent from zero to full load condition. But conduction loss is more due to high circulating energy thus reducing the system efficiency. Moreover a variable frequency control method makes the control circuits more complicated than those using the Pulse Width Modulation (PWM) control method. Thus, DC drive has lower efficiency when it operates on light loads. Approach: To improve the efficiency of the DC drive under light loads, a PWM-controlled quasi-resonant converter is proposed .It has simple control circuits and less conduction loss compared to a half-bridge LLC resonant converter under light load conditions. The proposed converter has a half-bridge LLC resonant converter along with an auxiliary circuit. The load regulation of the proposed converter can be achieved by an auxiliary circuit. Thus the proposed converter is expected to be suitable sustaining power module for the efficiency enhancement of DC drives. As the magnetizing inductance of the proposed converter is larger the circulating energy is considerably reduced under light load conditions. In this study the operational principle, design and modeling of QRC DC-DC converters for DC drives are presented. The PWM controlled quasi resonant converter is implemented using PIC microcontroller 16F184A. Results: The capacitor filter in the output is replaced by pi filter to produce DC with minimum ripple. The experimental results and simulation results are compared. This converter has the advantages like reduced number of switches, reduced transformer and filter size, reduced ripple, reduced switching losses, reduced switching stresses and increased power density. Conclusion: The experimental results closely agree with the simulation results.
\end{abstract}

Key words: Zero voltage switching, DC to DC converter, PIC microcontroller, pulse width modulation

\section{INTRODUCTION}

For the DC motors operating in the textile mills high efficiency is needed primarily under light load conditions. Resonant converters have miniaturization, high efficiency and low noise (Xie et al., 2007; Xu et al., 2006) but a large variation in switching frequency is needed to control the output voltage. These converters have size reduction and noise problems (Zhang et al., 2006; Eid et al., 2006; Fathy et al., 2006; Yao et al., 2004; Singh et al., 2002; Y. Ren et al., 2003; Singh et al., 2002). A half-bridge LLC resonant converter has many improvements over previous topologies (Hu et al., 2005; Yang et al., 2002). In the case of light load conditions, high circulating energy and variable frequency control method reduces the system efficiency. Thus, the PDP (Han et al., 2006;
Lee, 2007; 2008; Han et al., 2002) has lower efficiency. (Webber, 2004). In case of DC drives when they operate on light loads efficiency is very low. In order to improve the efficiency under light loads a PWM-controlled quasi-resonant converter is proposed which has simpler control circuits and less conduction loss (Xie et al., 2007; Xu et al., 2006) compared to a half-bridge LLC resonant converter under light load conditions. The circuit diagram of proposed converter is shown in Fig. 1. In this proposed converter the bidirectional auxiliary circuit consists of a two auxiliary MOSFETs $A_{1}$ and $A_{2}$, auxiliary inductor $L_{A}$ and auxiliary capacitor $C_{A}$. The main circuit consists of two main MOSFETs $\mathrm{Q}_{1}$ and $\mathrm{Q}_{2}$, A transformer is used for isolation as well as to step down the voltage. The secondary side consists of a full wave uncontrolled rectifier with a voltage doubler circuit. 


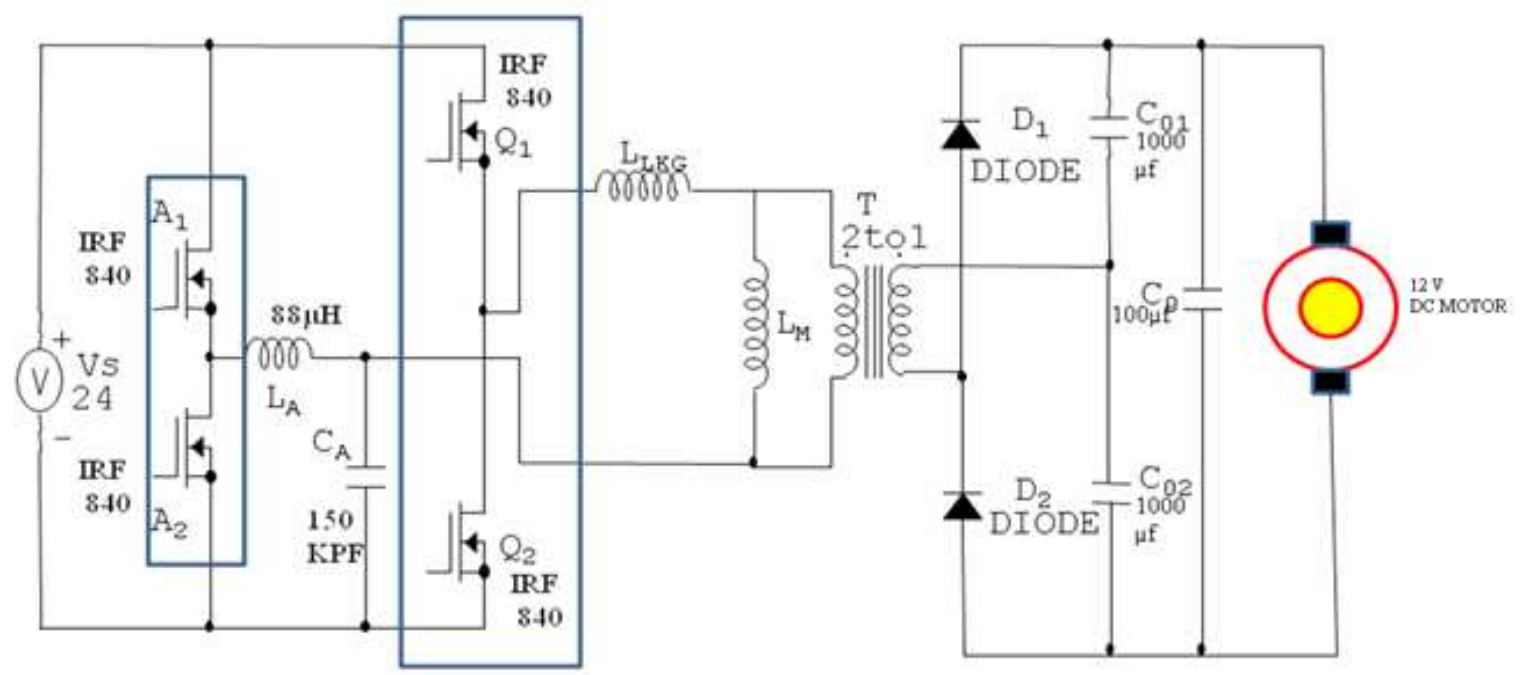

Fig. 1: Proposed PWM Controlled Quasi Resonant DC-DC Converter for DC drives under light load

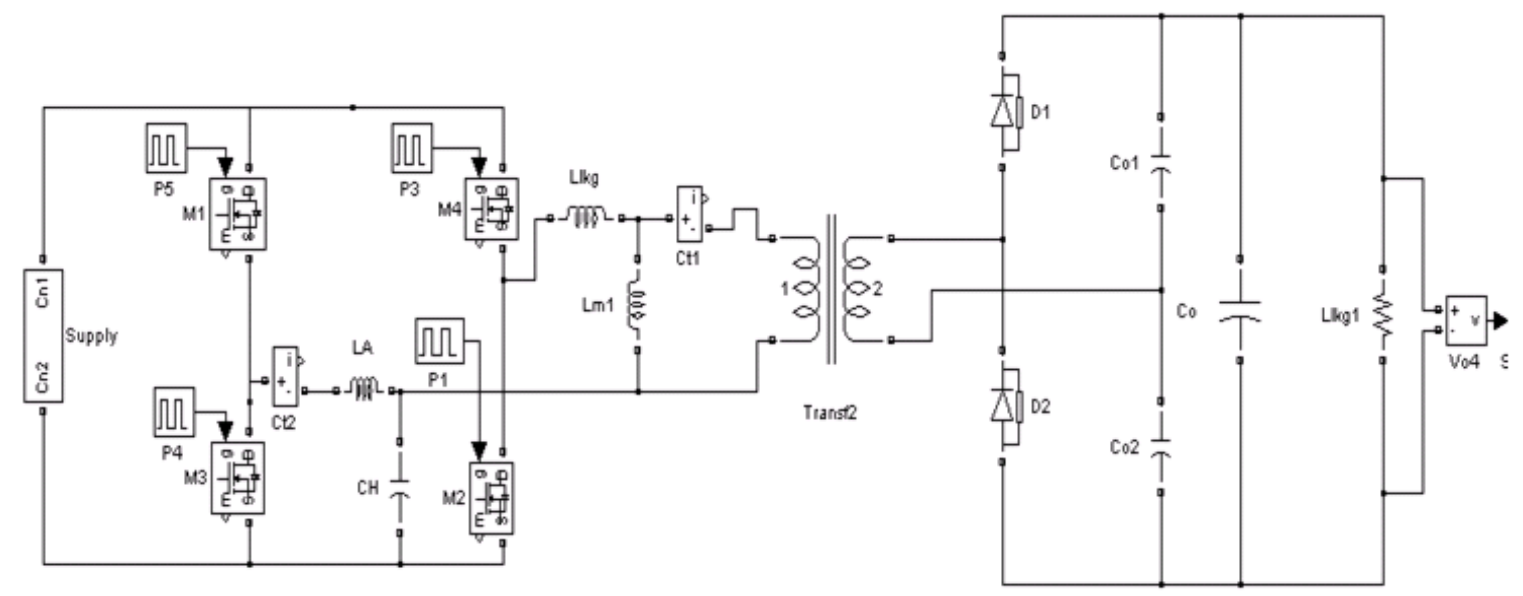

(a)
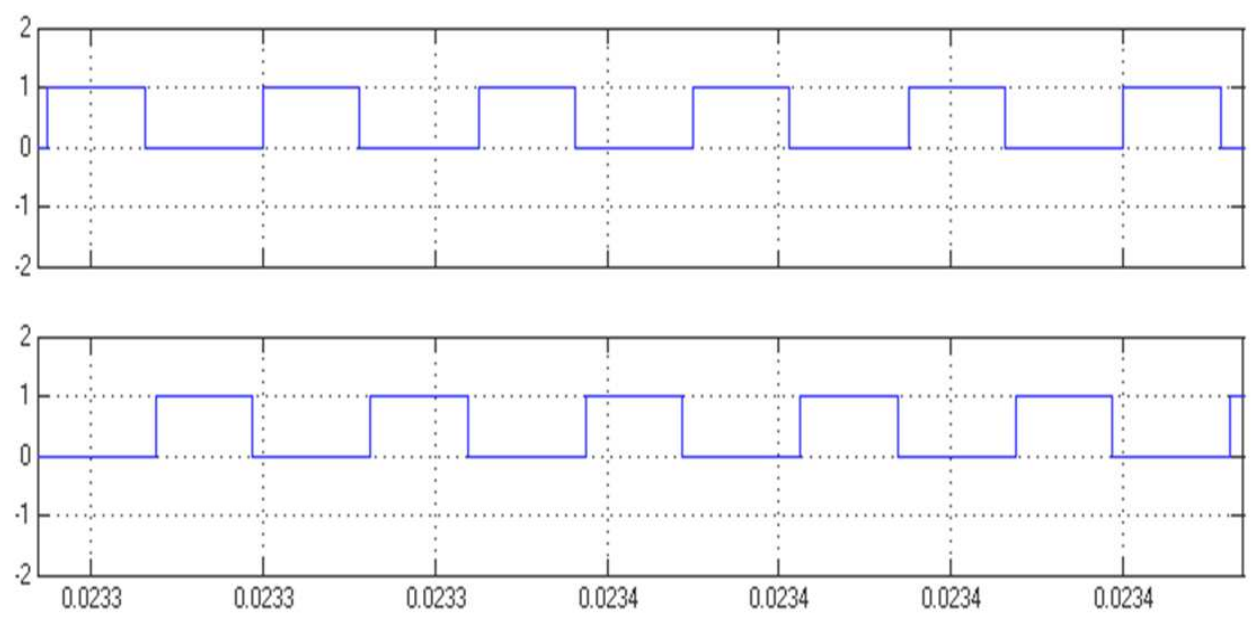

(b)

1731 
J. Computer Sci., 8 (10): 1730-1738, 2012

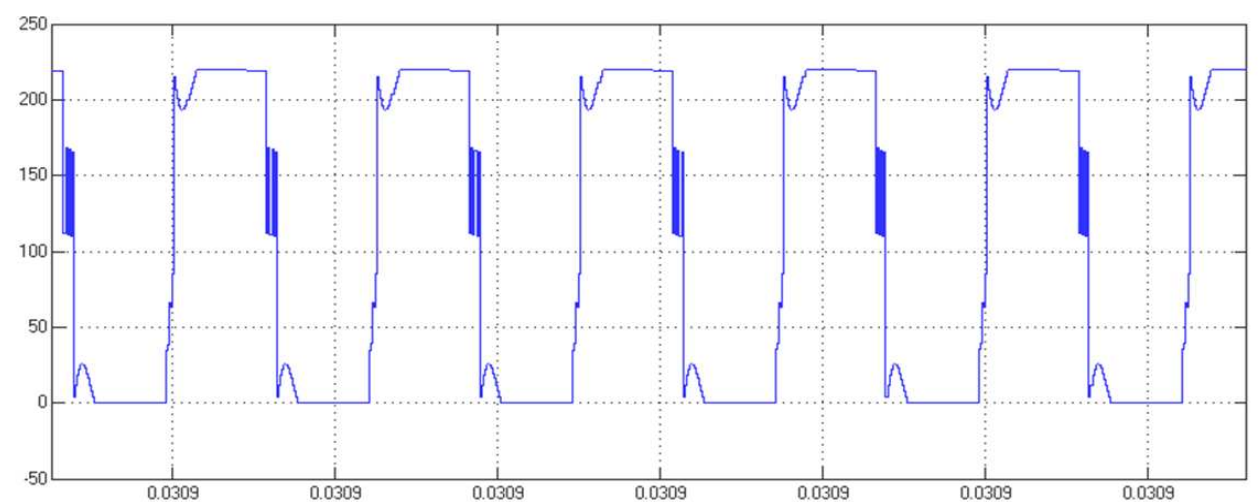

(c)

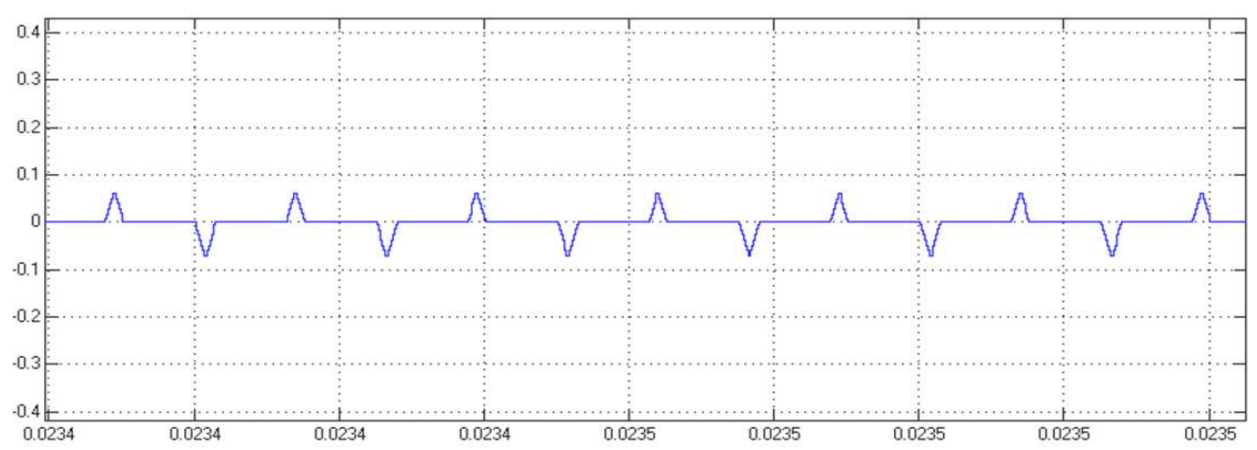

(d)
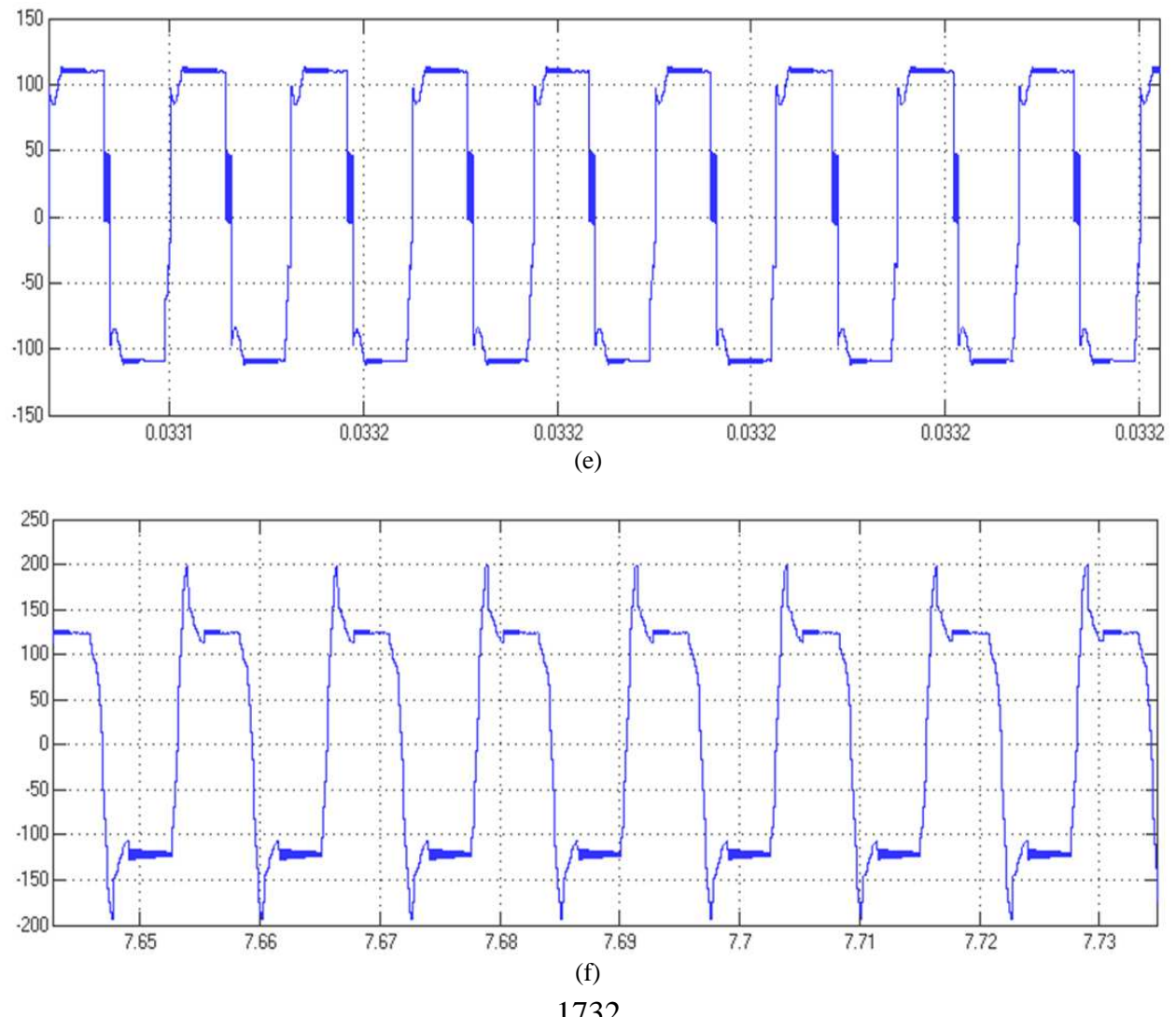
J. Computer Sci., 8 (10): 1730-1738, 2012

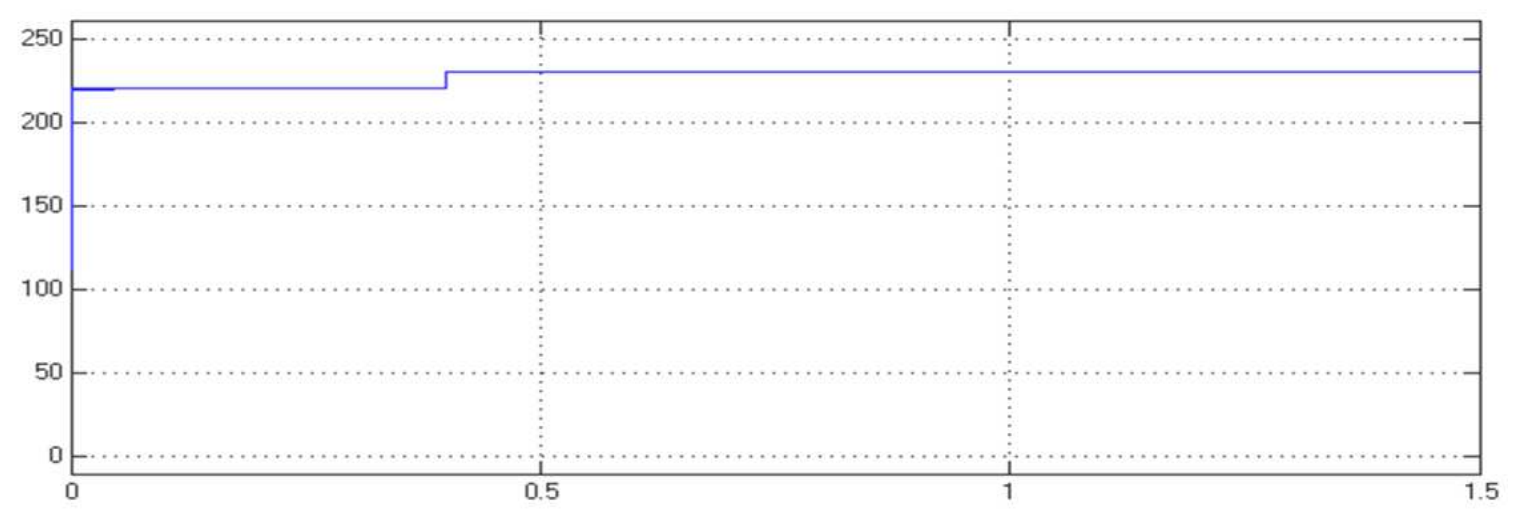

(g)

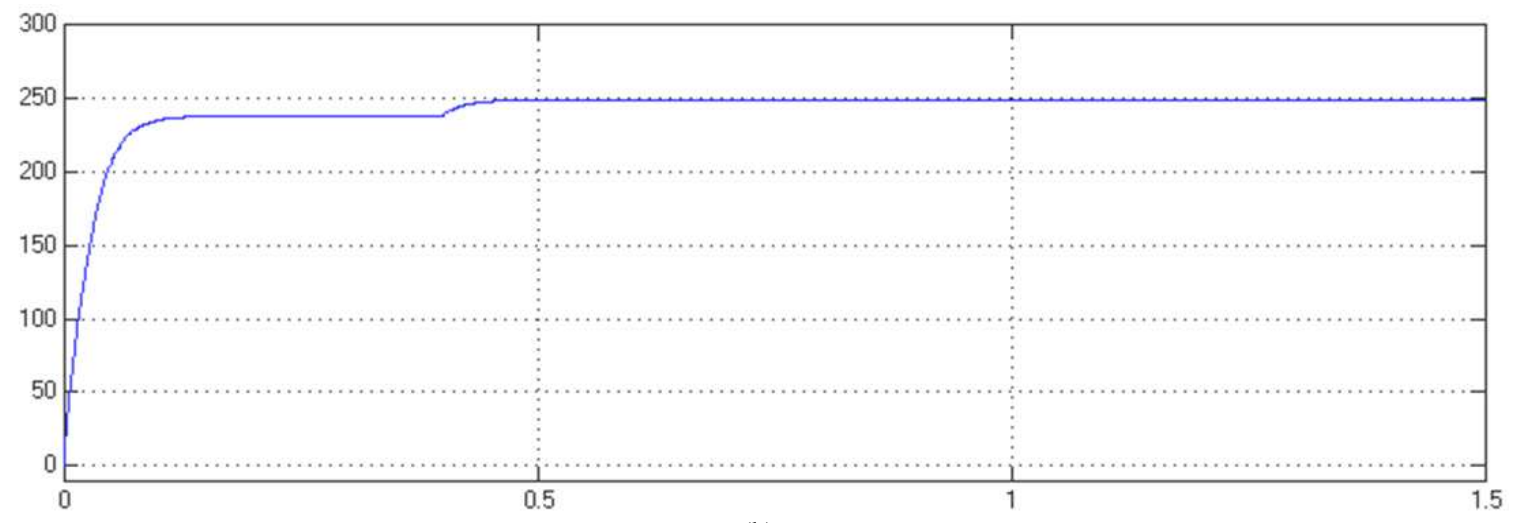

(h)

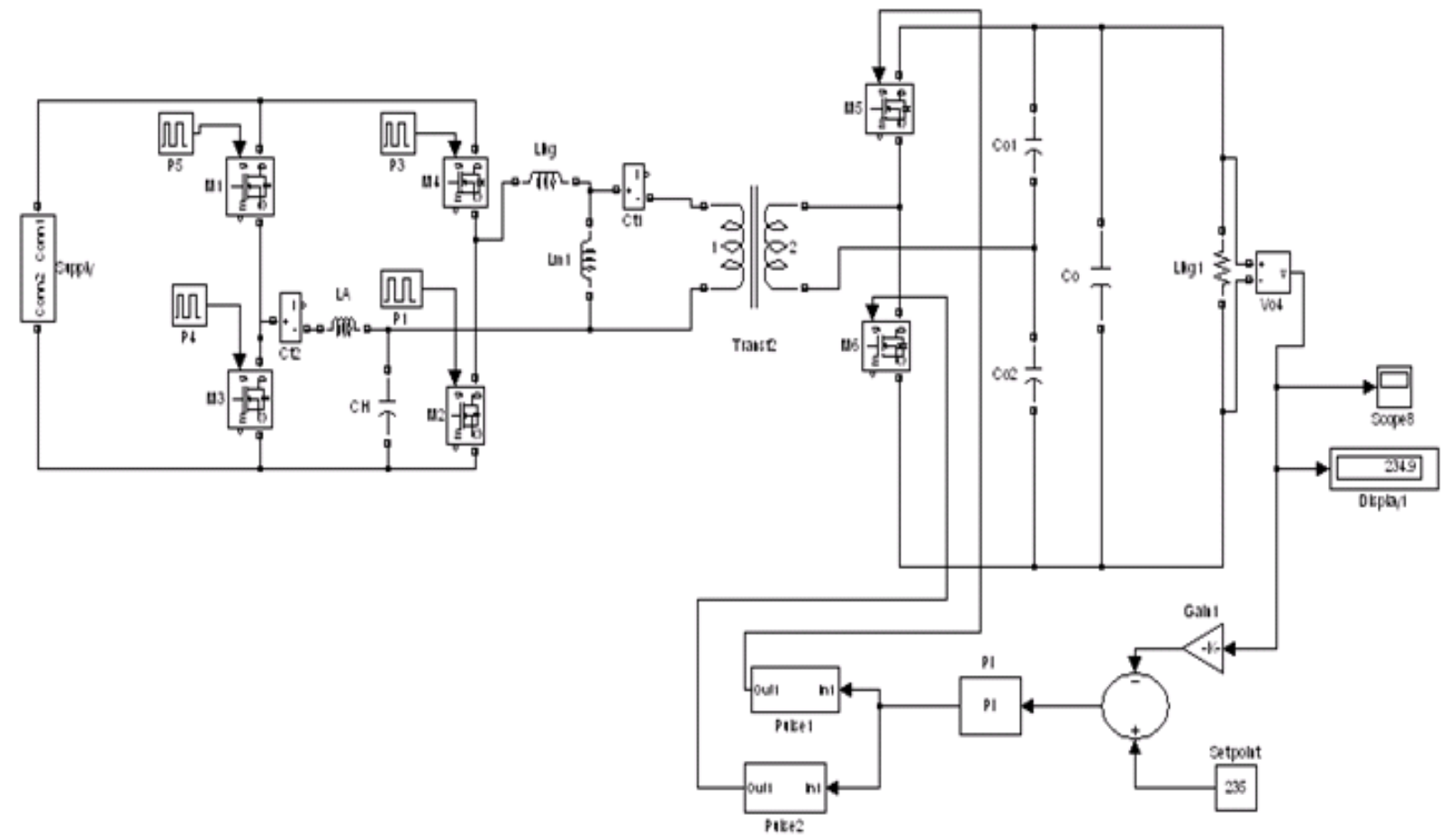

(i) 
J. Computer Sci., 8 (10): 1730-1738, 2012

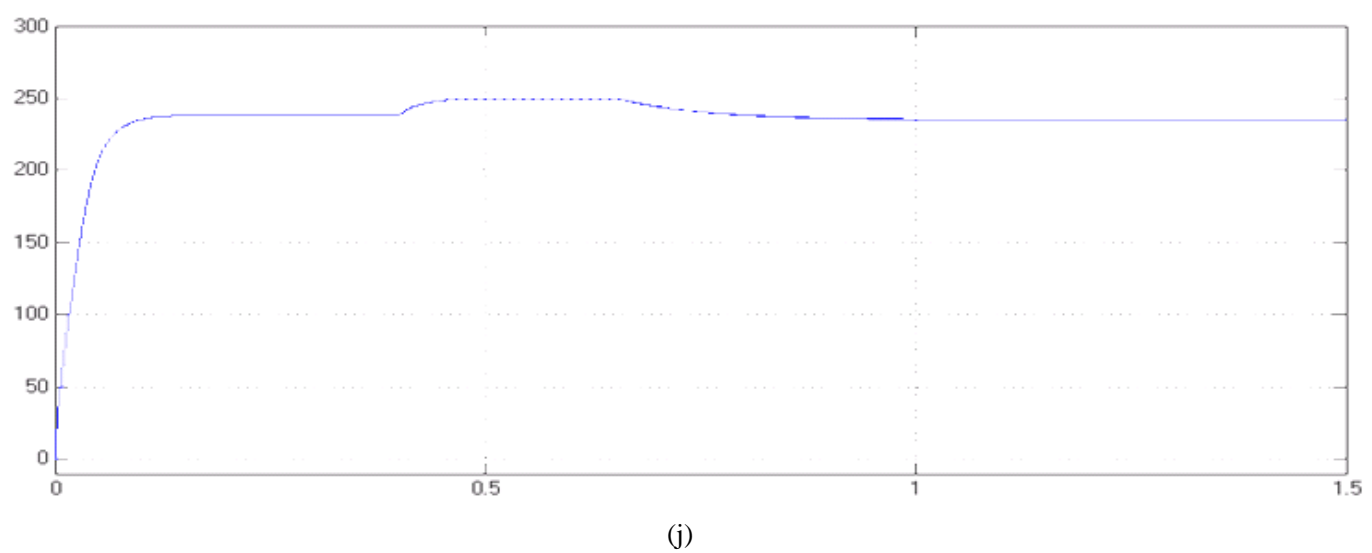

Fig. 2: (a) Open Loop Controlled DC to DC Converter (b) Driving pulses for M2 and M4 (c) Voltage across M4 switch. (d) Current through La inductor (e) Transformer primary side voltage (f) Transformer secondary side voltage (g) Input voltage with disturbance. (h) Output voltage with disturbance (i) Closed loop circuit model (j) Dc output voltage with disturbance

Due to the large inductance, the $\mathrm{ZVS}$ of $\mathrm{Q}_{1}$ and $\mathrm{Q}_{2}$ is easily achieved even at light load conditions. When the DC motor is operating on light loads, high efficiency is needed in some industrial application. The circulating energy of the proposed converter is considerably reduced under light load conditions. In the proposed converter, the output voltage can be regulated by controlling the voltage across the primary resonant capacitor while two main switches are operating at a fixed duty ratio and fixed switching frequency.

Simulation results: Digital simulation is done using Matlab and the results are presented here. Open loop controlled DC to DC converter is shown in Fig. 2a. Driving pulses for M2 and M4 is shown in Fig. $2 b$. Voltage across M4 switch is shown in Fig. 2c.

Current through $\mathrm{La}$ inductor is shown in Fig. 2d. Transformer primary side voltage is shown in Fig. 2e. Transformer secondary side voltage is shown in Fig. $2 \mathrm{f}$. Input voltage with a step disturbance is shown in Fig. $2 \mathrm{~g}$. Output voltage with a step disturbance is shown in Fig. $2 \mathrm{~h}$. The output voltage increases with the increase in the input voltage. When the input voltage was disturbed and increased at 0.4 sec., the output voltage also increased from $240 \mathrm{~V}$ to $250 \mathrm{~V}$ at $0.4 \mathrm{sec}$ and settles at $250 \mathrm{~V}$. In order to maintain the required output level irrespective of supply disturbances, closed control is required. The simulink model of closed loop system is shown in Fig. 2i. Output voltage is sensed and it is compared with the reference voltage. The error is processed through a PI controller. A controlled rectifier is recommended at the output to regulate the output voltage. When the output voltage increases, the error increases and the pulse width applied to the MOSFETs of the rectifier decreases to maintain the output voltage constant. There is a step rise in the input. In order to regulate the output, controlled switches M5 and M6 are used in the secondary side of the transformer instead of diodes. The output voltage is measured and compared with the reference value and the error signal is fed to PI controller. The control signal obtained from the PI controller circuit is fed to PWM controller circuit which generates the required driving pulses for the MOSFETs M5 and M6. By PWM control of M5 and M6 the output voltage can be maintained at the required level. The output voltage in closed loop control is shown in Fig. 2j. As observed from Fig. $2 \mathrm{j}$.

In closed loop control, whenever the input voltage is increases, the output voltage also slightly rises but comes back to the original value $240 \mathrm{~V}$ at $0.65 \mathrm{Sec}$. Therefore the output voltage is maintained constant irrespective of changes in the supply voltage. The output voltage reduces to the steady state value. Thus the steady state error is reduced by using closed loop system.

Hardware implementation: In order to verify the effectiveness of the proposed converter configuration and its control strategy, a cost effective new PWM controlled quasi resonant converter has been developed, simulated and successful implemented in real time in open loop using PIC 16F877A Micro controller for a prototype.

The hardware for PWM-controlled Quasi resonant converter is fabricated and tested in the laboratories. The overview of hardware model is shown in Fig. 3a. Control circuit is shown in Fig. 3b. The complete hardware model is shown in Fig 3c. The voltage across the MOSFET is shown in Fig. 3d. Transformer primary side voltage is shown in Fig 3e.The output waveform is complement of the driving pulse. The voltage across the secondary is shown in Fig. 3f. DC output voltage is shown in Fig. $3 \mathrm{~g}$. 
J. Computer Sci., 8 (10): 1730-1738, 2012

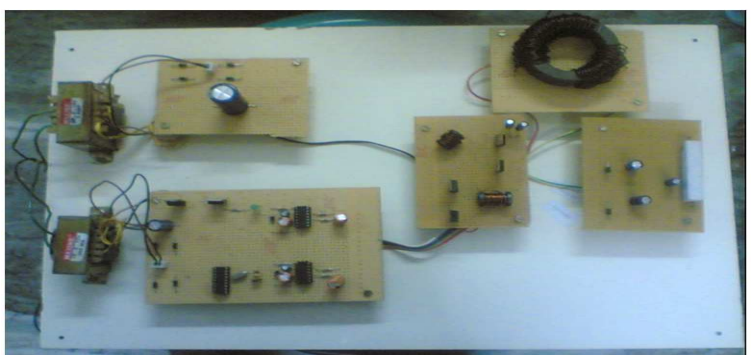

(a)

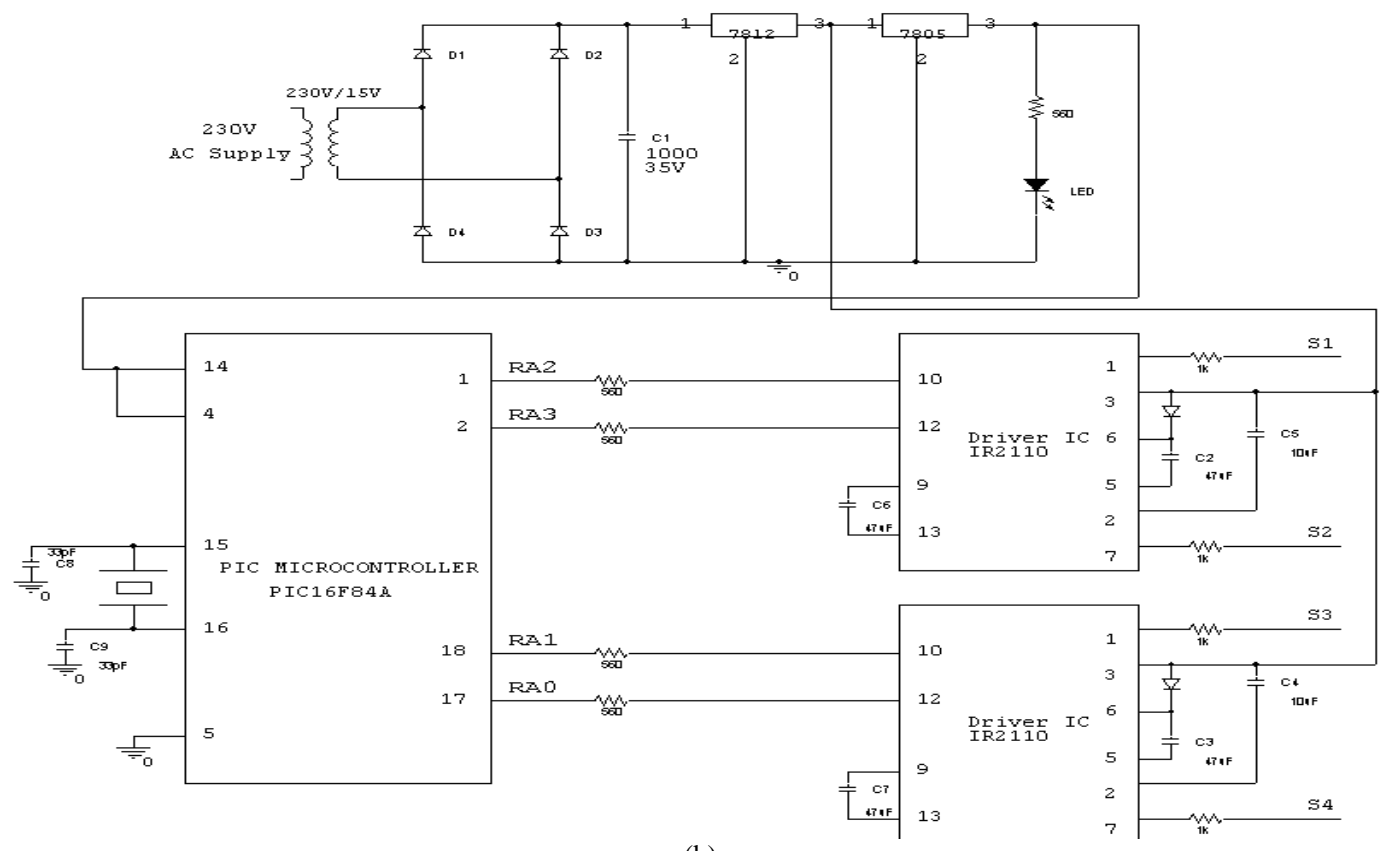

(b)

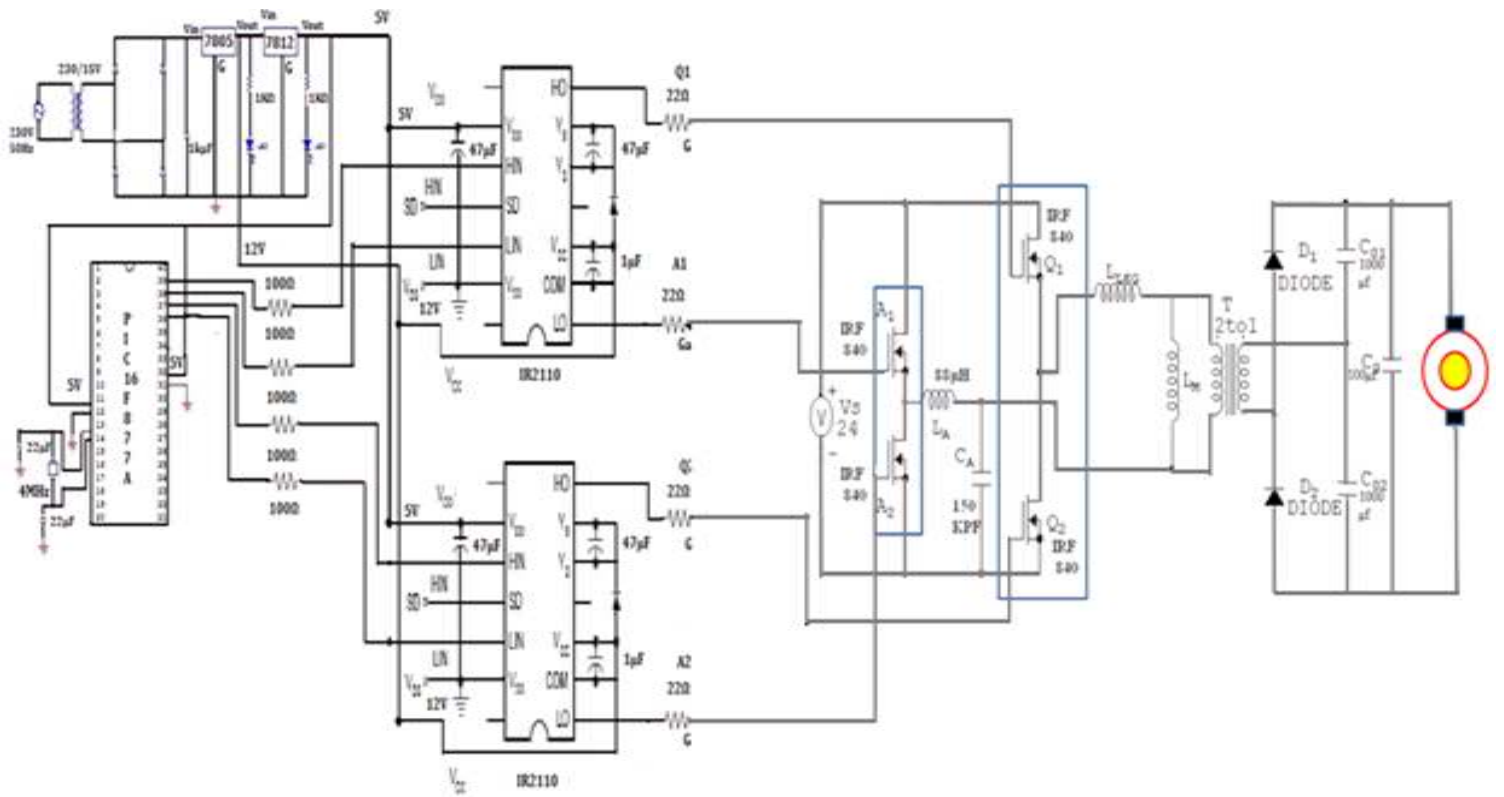

(c) 
J. Computer Sci., 8 (10): 1730-1738, 2012

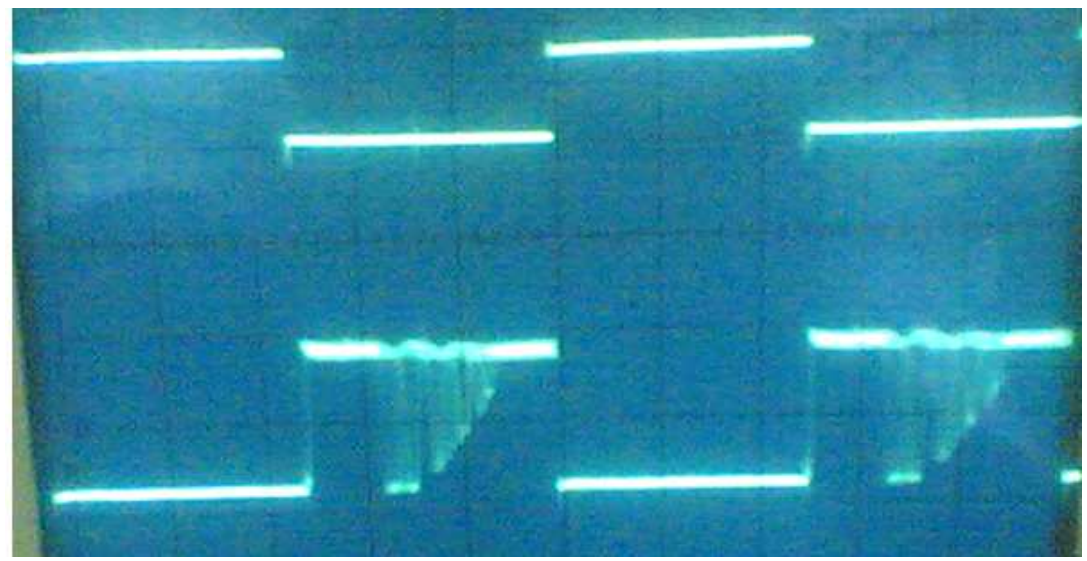

(d)

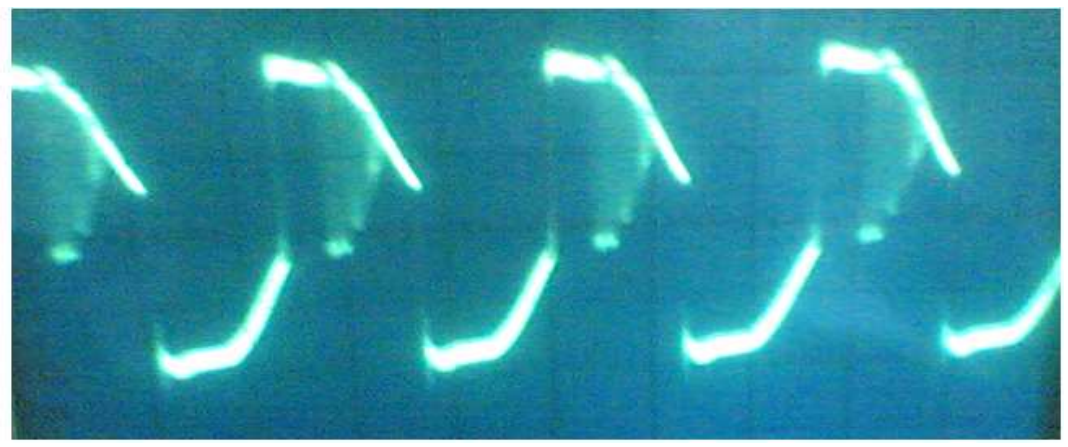

(e)

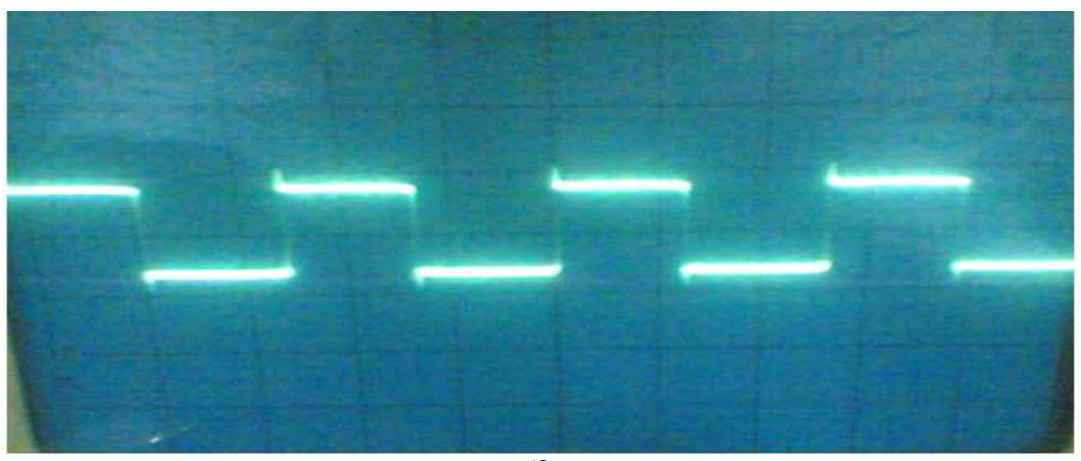

(f)
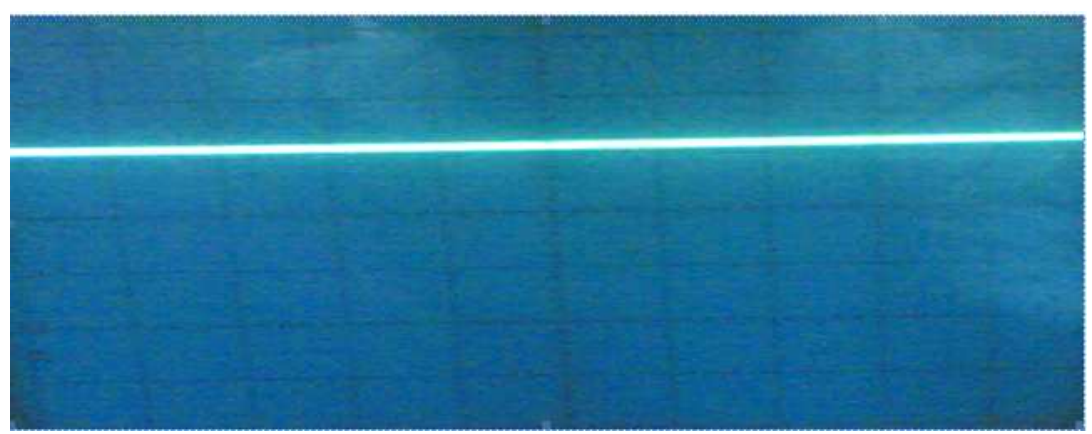

(g)

1736 
J. Computer Sci., 8 (10): 1730-1738, 2012



(h)

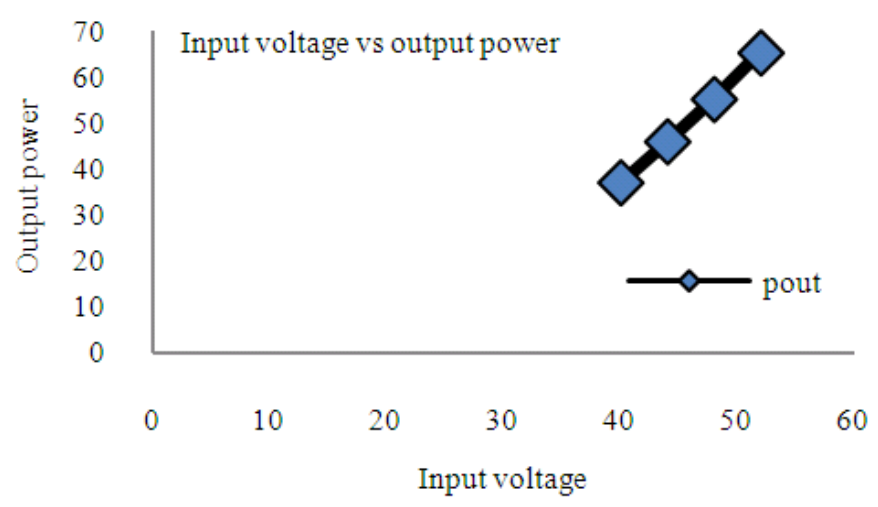

(i)

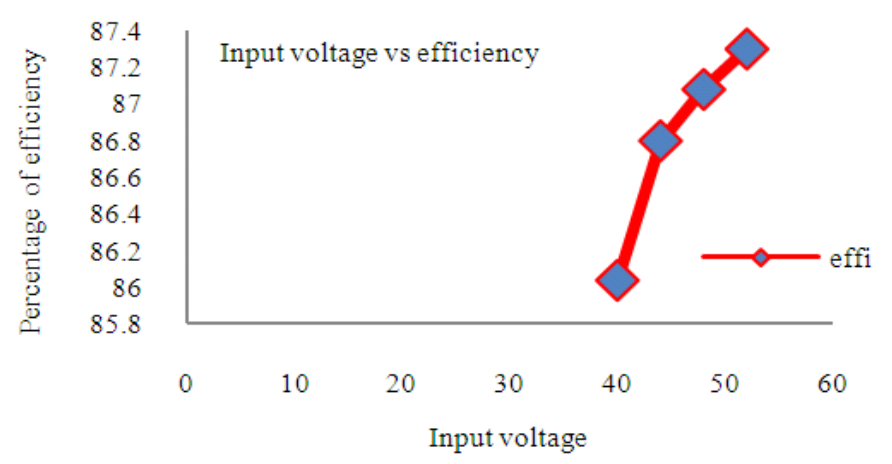

(j)

Fig. 3: (a) Overview of Hardware kit (b) Control circuit (c) Complete hardware diagram (d) Vgs and Vds voltage (e) Transformer primary side voltage (f) Transformer secondary side voltage (g) Output voltage (h) Input voltage Vs Output voltage (i) Input voltage Vs Output power (j) Input voltage Vs Efficiency

It can be seen that the DC output voltage is free from ripple. Input voltage Vs Output voltage characteristics are shown in Fig. 3h. Input voltage Vs Output Power characteristics are shown in Fig. 3i. Input voltage Vs Efficiency is shown in Fig. 3j. From the simulation results and oscillograms of the experimental results it can be seen that the experimental results coincide with the simulation results.
Figure 3 a shows the overview of the hardware kit, which consists of the input diode rectifier, half bridge LLC resonant converter with auxiliary circuit, high frequency transformer and output rectifier with voltage doublers shows the input diode rectifier, filter capacitor, voltage regulators, PIC 16F877A microcontroller and IR 2110 drivers. Table 1 shows hardware components of power circuit. 
Table 1: Hardware components of power circuit

\begin{tabular}{lll}
\hline Name of the components & Product no/value & Quantity \\
\hline $\mathrm{Q}_{1}$ and $\mathrm{Q}_{2}$ & $I R F 840$ & 2 \\
$\mathrm{Q}_{\mathrm{A} 1}$ and $\mathrm{Q}_{\mathrm{A} 2}$ & $\mathrm{IRF} 840$ & 2 \\
Auxillary inductor & $88 \mathrm{mf}$ & 1 \\
Auxillary capacitor & $150 \mathrm{Kpf}$ & 1 \\
Driver & $\mathrm{IR} 2110$ & 2 \\
Voltage regulator & 7812 and 7805 & 2 \\
Transformer & $2: 1$ isolation type & 1 \\
Capacitors & $1000 \mathrm{mF}$ & 2 \\
\hline
\end{tabular}

\section{CONCLUSION}

The PWM controlled Quasi resonant DC-DC converter for an efficiency enhancement of a DC motor is simulated using matlab simulink and implemented using PIC microcontroller 16F184A. The capacitor filter in the output is replaced by pi filter to produce DC with minimum ripple. This converter has the advantages like reduced number of switches, reduced transformer and filter size, reduced ripple, reduced switching losses, reduced switching stresses and increased power density.

The scope of this study is the simulation and implementation of quasi resonant DC-DC converter using PIC microcontroller. The experimental results closely agree with the simulation results. The efficiency of DC drive under light load conditions is improved.

\section{REFERENCES}

Eid, A., K.J. Choi, H.W. Lee and M. Nakaoka, 2006. A novel edge-resonant soft switching PWM controlled high frequency inverter with minimum circuit components. Proceedings of the International Conference on Power Electronics and Drives Systems, Nov. 28-Dec. 1, IEEE Xplore Press, Kuala Lumpur, pp: 101-106. DOI: 10.1109/PEDS.2005.1619668

Fathy, K., K. Morimoto, T. Doi, T. Doi, H. Ogiwara and H.W. Lee et al., 2006. A divided voltage halfbridge high frequency soft-switching PWM DCDC converter with high and low side DC rail active edge resonant snubbers. Proceedings of the CES/IEEE 5th International Power Electronics and Motion Control Conference, Aug. 14-16, IEEE Xplore Press, Shanghai, pp: 1-5. DOI: 10.1109/IPEMC.2006.4778201

Han, S.K., J.Y. Lee, G.W. Moon and M.J. Youn, 2006. IGBT-based cost-effective energy-recovery circuit for plasma display panel. IEEE Trans. Indu. Elec., 53: 1546-1554. DOI: 10.1109/TIE.2006.882018

Han, S.K., J.Y. Lee, G.W. Moon, M.J. Youn and C.B. Park et al., 2002. A new energy-recovery circuit for plasma display panel. Elec. Lett., 38: 790-792. DOI: 10.1049/el:20020547
Hu, Y., Z. Lu, L. Hang, Z. Qian and G. Huang, 2005. Three-level LLC series resonant DC-DC converter. IEEE Trans. Power Elec., 20: 781-789. DOI: 10.1109/TPEL.2005.850921

Lee, J.Y., 2007. An improved magnetic-coupled ac-pdp sustain driver with dual recovery paths. IEEE Trans. Indu. Elec., 54: 1623-1631. DOI: 10.1109/TIE.2007.894766

Lee, W.J., S.W. Choi, C.E. Kim and G.W. Moon, 2008. A New PWM-controlled quasi-resonant converter for a high efficiency PDP sustaining power module. IEEE Trans. Power Elect., 23: 1782-1790. DOI: 10.1109/TPEL.2008.924613

Ren, Y., M. Xu, Y. Meng and F.C. Lee, 2003. Novel PWM-controlled resonant converter. Proceedings of the 18th Annual Applied Power Electronics Conference Exposition, Feb. 9-13, pp: 420-425.

Singh, K.J., G. Bachmann, S.R. Doradla, P. Mutschler and R. Ghosh, 2002. An LCLC resonant DC-DC converter with PWM control-analysis, simulation and implementation. Proceedings of the 17th Annual IEEE Applied Power Electronics Conference and Exposition, Mar. 10-14, IEEE Xplore Press, Dallas, TX., pp: 1113-1119. DOI: 10.1109/APEC.2002.989383

Webber, L.F., 2004. Do LCD TVs really last longer than PDP TVs. Inform. Display, Soc. Inform. Display, 20: 12-17.

Xie, X., J. Zhang, C. Zhao, Z. Zhao and Z. Qian, 2007. Analysis and optimization of LLC resonant converter with a novel over-current protection circuit. IEEE Trans. Power Elec., 22: 435-443. DOI: 10.1109/TPEL.2006.889919

$\mathrm{Xu}, \mathrm{X}$., A.M. Kharnbadkone, T.M. Leong and R. Oruganti, 2006. A 1- MHz zero-voltage-switching asymmetrical half-bridge DC/DC converter: Analysis and design. IEEE Trans. Power Elec., 21: 105-113. DOI: 10.1109/TPEL.2005.861109

Yang, B., F.C. Lee, A.J. Zhang and G. Huang, 2002. LLC resonant converter for front end DC/DC conversion. Proceedings of the 17th Annual IEEE Applied Power Electronics Conference and Exposition, Mar. 10-14, IEEE Xplore Press, Dallas, TX., pp: 1108-1112. DOI: 10.1109/APEC.2002.989382

Yao, K., M. Xu, Y. Ren, J. Zhou and Y. Qiu et al., 2004. Quasi-resonant converters for highfrequency voltage regulator applications. Proceedings of the 19th Annual IEEE Applied Power Electronics Conference and Exposition, Feb. 22-26, IEEE Xplore Press, pp: 891-897. DOI: 10.1109/APEC.2004.1295928

Zhang, J., X. Xie, X. Wu, G. Wu and Z. Qian, 2006. A novel zero-current-transition full bridge DC/DC converter. IEEE Trans.Power Elec., 21: 354-360. DOI: 10.1109/TPEL.2005.869748 